\title{
Oxygen stability in the new [FeFe]-hydrogenase from Clostridium beijerinckii SM10 (CbA5H)
}

\author{
Simone Morrał, Mariaconcetta Arizził, Francesca Valetti*, Gianfranco Gilardi* \\ Department of Life Sciences and Systems Biology, University of Torino, Via Accademia Albertina 13, Torino 10123, Italy.
}

Supporting Information Placeholder

\begin{abstract}
The newly isolated [FeFe]-hydrogenase CbA5H was characterized by FTIR spectroscopy coupled to enzymatic activity assays. This showed for the first time that in this enzyme the oxygen-sensitive active state $\mathrm{H}_{\mathrm{ox}}$ can be simply and reversibly converted to the oxygen-stable inactive $\mathrm{H}_{\text {inact }}$ state. This suggests that oxygen sensitivity is not an intrinsic feature of the catalytic center of [FeFe]-hydrogenases (H-cluster), opening new challenging perspectives on the oxygen sensitivity mechanism as well as new possibilities for the exploitation in industrial applications.
\end{abstract}

$[\mathrm{FeFe}]$-hydrogenases are a vast class of redox enzymes that catalyze reversibly the reaction of $\mathrm{H}_{2}$ evolution by the catalytic center H-cluster (Fig. 1A). ${ }^{1}$ Several hundreds of sequenced genes can potentially express enzymes that are members of this class, ${ }^{2}$ but so far only few of them have been characterized. ${ }^{3-5}$ Thus, the isolation and characterization of novel [FeFe]-hydrogenases is expected to provide novel important information. ${ }^{6,7,8}$

A common feature to all [FeFe]-hydrogenases is oxygen sensitivity: these enzymes are found in strict anaerobic or facultative anaerobic organisms and they are inactivated by molecular oxygen. Oxygen inactivation is a complex mechanism, still under active debate. Variability in the inactivation rate has been described between enzymes from different organisms. ${ }^{9-15}$

Oxygen sensitivity is the main factor that hinders the exploitation of [FeFe]-hydrogenases for applicative purposes ${ }^{3,16,17}$ as generally exposure to $\mathrm{O}_{2}$ leads to irreversible inactivation on a time scale of seconds. This is believed to be due to a partial degradation of the H-cluster, via a multistep process. ${ }^{14,15,18}$ Partial reversible reactivation in some [FeFe]-hydrogenases was previously reported by electrochemical studies, but resulting from a very complex interplay of electrode potential and anaerobic/aerobic inactivation processes. ${ }^{12,13,19}$ Protein engineering was used to generate [FeFe]-hydrogenase mutants with slightly decreased oxygen sensitivity. ${ }^{20}$
So far, the clearest exceptions to irreversible inactivation are the [FeFe]-hydrogenases from Desulfovibrio desulfuricans $(\mathrm{DdH}),{ }^{21,22}$ D. vulgaris $(\mathrm{DvH})^{23,24,25}$ and $D$. gigas. ${ }^{26} \mathrm{DdH}$ is known to produce the inactive and oxygen-stable redox state called $\mathrm{H}_{\text {inact }}$ (Fig. 1B). ${ }^{21,22}$ This state was originally identified in $\mathrm{DdH}$ preparations that have been purified aerobically. ${ }^{27}$

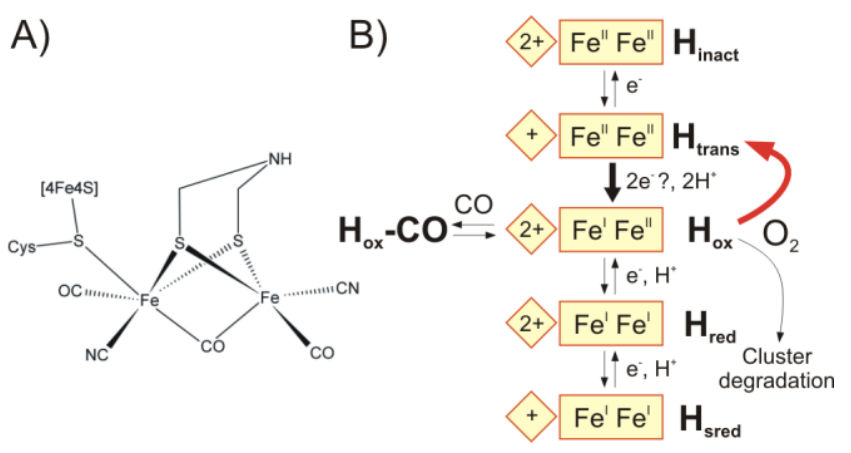

Figure 1. A) Scheme of the H-cluster structure. B) Scheme of the H-cluster redox states and their interconversion, as known in DdH (black arrows). ${ }^{4,21,22}$ The red arrow marks the reversible transition described in this paper in $\mathrm{CbA5H}$.

Spectroscopic experiments showed that this form of the $\mathrm{DdH}$ enzyme can be activated by a reductive treatment but, subsequently, the $\mathrm{H}_{\text {inact }}$ state cannot be formed again. ${ }^{13,21,22}$ Also, when the activated protein is exposed to oxygen, the H-cluster is degraded. ${ }^{13,28}$ In particular, spectro-electrochemical experiments on $\mathrm{DdH}$ have shown that $\mathrm{H}_{\text {inact }}$ can be reversibly converted into the intermediate state $\mathrm{H}_{\text {trans }}$ by a single electron reduction and that, subsequently, $\mathrm{H}_{\text {trans }}$ can be converted irreversibly into the active state $\mathrm{H}_{\mathrm{ox}}$ by a two electrons reduction. Attempts to prepare intentionally in vitro the $\mathrm{H}_{\text {inact }}$ state were usually unsuccessful ${ }^{21,22}$, with the exception of a single report of a complex procedure ${ }^{28}$ that could not be successfully reproduced ${ }^{21,22}$. Cyclic voltammetry experiments showed the reversible formation of an inactive species under anaerobic conditions, but no spectroscopic evidence has determined its identity. ${ }^{9,16,29}$ 
In this work, we report the first characterization of a novel monomeric [FeFe]-hydrogenase from the strain Clostridium beijerinckii SM10 that was isolated from an efficient bio-hydrogen pilot plant fed with vegetable wastes. ${ }^{6}$ The gene sequence was deposited in the NCBI database (accession KX147468) and the enzyme was recombinantly produced in $E$. coli under strict anaerobic conditions. ${ }^{30,31}$

Phylogenetically, the enzyme belongs to cluster A5 and has a modular structure M2c. ${ }^{5,32}$ For this reason, the enzyme has been named as $\mathrm{CbA5H}$. Starting from the $\mathrm{N}$ terminus, it is composed by 1) a domain hosting the poorly characterized SLBB motif (soluble-ligandbinding $\beta$-grasp fold); ${ }^{33}$ 2) a domain hosting two [4Fe4S] centers that is homologous to bacterial ferredoxins and that is widely distributed in hydrogenases; 3 ) the $\mathrm{H}$-domain hosting the catalytic center $\mathrm{H}$-cluster, which shows high sequence similarity to other [FeFe]hydrogenases (See Fig. S1).

When the enzyme is purified anaerobically in the presence of $2 \mathrm{mM}$ sodium dithionite as oxygen scavenger, it is active both in the $\mathrm{H}_{2}$ uptake assay and the $\mathrm{H}_{2}$ evolution assay, with rates that are $158 \pm 34$ and $751 \pm 91$ $\mu \mathrm{mol} \mathrm{H}_{2} \mathrm{~min}^{-1} \mathrm{mg}$ protein ${ }^{-1}$, respectively.

A detailed FTIR analysis was performed to characterize the specific influence of the protein environment on the H-cluster properties in this hydrogenase. The assignment of the various signals to known redox states as discussed below, was obtained by comparison to data previously reported for other [FeFe]-hydrogenases. ${ }^{21,22,33}$

The anaerobically purified enzyme mainly equilibrated in the $\mathrm{H}_{\mathrm{ox}}$ state, with minor contributions from the $\mathrm{H}_{\text {red }}$ state (fig. 2A). The FTIR spectral signature of the $\mathrm{H}_{\mathrm{ox}}$ is composed by five peaks at 2091, 2080, 1964, 1940 and $1800 \mathrm{~cm}^{-1}$. The FTIR spectral signature of $\mathrm{H}_{\text {red }}$ was more difficult to identify, due to low intensity signals that could be identified at 2040, 1915 and $1893 \mathrm{~cm}^{-}$ 1. Treatment of this sample with carbon monoxide caused a complete shift to the $\mathrm{H}_{\mathrm{ox}}-\mathrm{CO}$ state (fig. 2B), whose spectral signature is composed by six peaks at 2094, 2090, 2016, 1971, 1963 and $1807 \mathrm{~cm}^{-1}$.

These data show that the structure of $\mathrm{CbA} 5 \mathrm{H} \mathrm{H}$ cluster is highly consistent with that of other $[\mathrm{FeFe}]-$ hydrogenases: ${ }^{21,22,34,35}$ two terminal $\mathrm{CO}$, two terminal $\mathrm{CN}$ and a bridging $\mathrm{CO}$ are coordinated to the $[2 \mathrm{Fe}]$ subcluster in the $\mathrm{H}_{\mathrm{ox}}$ state; upon reduction, the bridging $\mathrm{CO}$ is shifted to a semi-bridging position (the signal at 1800 $\mathrm{cm}^{-1}$ in $\mathrm{H}_{\mathrm{ox}}$ shifts to $1893 \mathrm{~cm}^{-1}$ in $\mathrm{H}_{\mathrm{red}}$ ); upon $\mathrm{CO}$ exposure, the new ligand binds to the vacant coordination of $\mathrm{Fe}_{\mathrm{d}}$, causing a vast rearrangement in the vibrational modes of all the ligands.

Much more interestingly, treatment of the anaerobically purified protein with different organic oxidants, such as thionine $\left(\mathrm{E}_{\mathrm{m} 7}=+60 \mathrm{mV}\right), 2,6-$ dichlorophenolindophenol (DCIP, $\mathrm{E}_{\mathrm{m} 7}=+220 \mathrm{mV}$ ) or air (i.e. oxygen) produce samples displaying an homo- geneous spectrum with the $\mathrm{H}_{\text {inact }}$ signature with signals at 2107, 2080, 2011, 1992 and $1840 \mathrm{~cm}^{-1}$ (fig. 2C, 2D, 2E). The $\mathrm{H}_{\text {inact }}$ could be reconverted to a mixture of $\mathrm{H}_{\mathrm{ox}}$ and $\mathrm{H}_{\text {red }}$ by reducing treatment with sodium dithionite or $\mathrm{H}_{2}$ (fig. $2 \mathrm{~F}$ and $2 \mathrm{G}$ ).

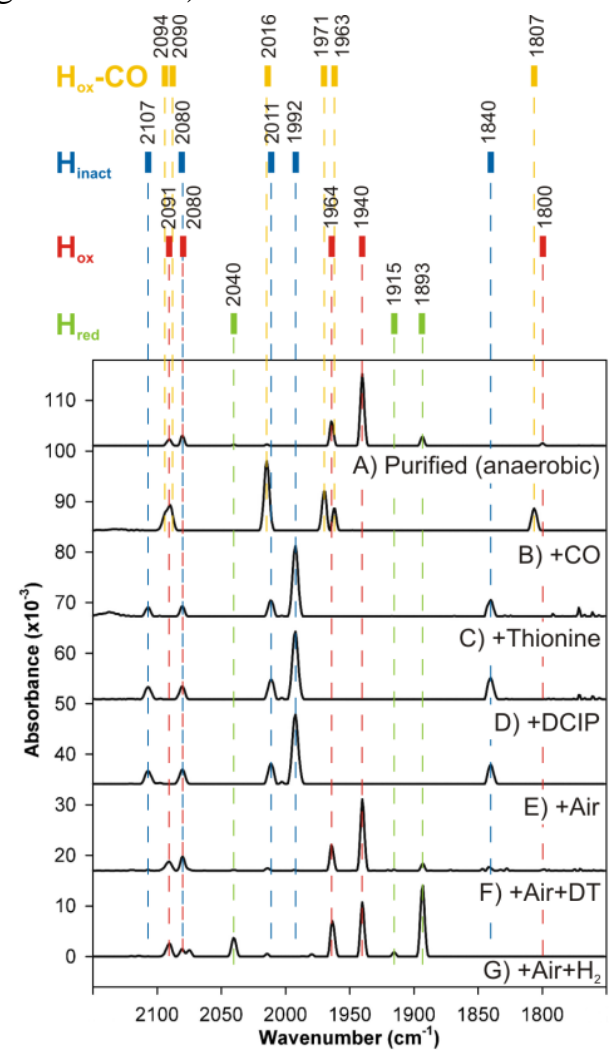

Figure 2. FTIR spectra of Clostridium beijerinckii [FeFe]hydrogenase $\mathrm{CbA5H}$. A) After anaerobic purification, without further treatment. B) After $\mathrm{CO}$ treatment. C) After thionine oxidation (8-fold molar ratio). D) After DCIP oxidation (24-fold molar ratio). D) After oxidation with air (10 min). E) After oxidation with air and reduction with sodium dithionite (10-fold molar ratio). F) After oxidation with air and reduction with $\mathrm{H}_{2}(50 \mathrm{~min})$. The protein concentration was $0.3-1 \mathrm{mM}$ and opportune scaling factors were applied to the spectra for simpler comparison, as follows: B) $\mathrm{x} 2$. C) x3.5. D) x1.8. E) x1.6. F) x1.2. G) x2.4 .

These first evidences show that in Clostridium beijerinckii $[\mathrm{FeFe}]$-hydrogenase it is possible to convert the $\mathrm{H}_{\mathrm{ox}}$ state into the $\mathrm{H}_{\text {inact }}$ state and that the conversion is spontaneous upon oxidation by thionine or DCIP or by the oxygen present in air, while this has never been observed in $\mathrm{DdH}$, the $\mathrm{H}_{\text {inact }}$ to $\mathrm{H}_{\mathrm{ox}}$ reaction being irreversible, according to FTIR evidences. ${ }^{21,22}$ More detailed experiments were carried out to correlate the spectral change to the catalytic rate of $\mathrm{CbA} 5 \mathrm{H}$. To confirm the functional properties of the different redox states of the H-cluster, the same sample was split: a part was used to acquire FTIR spectra (fig. 3) and the other part tested for $\mathrm{H}_{2}$ uptake activity (fig. 4).

As already presented above, the anaerobically purified enzyme was a catalytically active mixture of $\mathrm{H}_{\mathrm{ox}}$ and 
$\mathrm{H}_{\text {red }}$ (Fig. 3A and 4) and it could be pushed towards the inactive $\mathrm{H}_{\text {inact }}$ by air treatment (Fig. $3 \mathrm{~B}$ and 4). Subsequently, the enzyme could be completely reactivated by $\mathrm{H}_{2}$ treatment; after the reactivation, $\mathrm{CbA} 5 \mathrm{H}$ equilibrated again in a mixture of $\mathrm{H}_{\mathrm{ox}}$ and $\mathrm{H}_{\text {red }}$ states, where the reduced state was more abundant (Fig. 3C and 4).

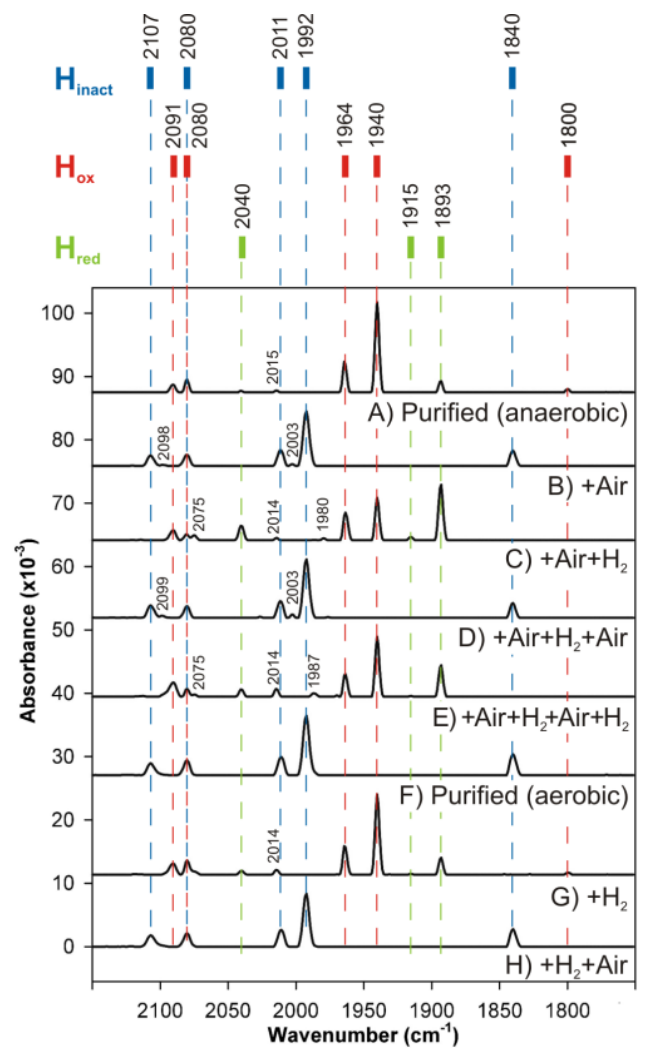

Figure 3. FTIR spectra of $\mathrm{CbA} 5 \mathrm{H}$ after anaerobic or aerobic purification and after various cycles of activation/inactivation. A) After anaerobic purification, without further treatment. B) The anaerobically purified sample after exposure to air $(10 \mathrm{~min})$. C) The anaerobically purified sample after exposure to air $(10 \mathrm{~min})$ followed by exposure to $\mathrm{H}_{2}(50 \mathrm{~min})$. D) The anaerobically purified sample after exposure to air (10 $\mathrm{min})$, followed by exposure to $\mathrm{H}_{2}$ (50 $\mathrm{min})$ and then air $(10 \mathrm{~min})$. E) The anaerobically purified sample after two cycles of exposure to air, followed by exposure to $\mathrm{H}_{2}$. F) After aerobic purification, without further treatment. G) The aerobically purified sample after exposure to $\mathrm{H}_{2}(50 \mathrm{~min})$. H) The aerobically purified sample after exposure to $\mathrm{H}_{2}(50 \mathrm{~min})$ followed by exposure to air (10 $\mathrm{min})$. The protein concentration was $0.8-1 \mathrm{mM}$ and opportune scaling factors were applied to the spectra for simpler comparison, as follows: C) x1.5. D) x1.5. E) x1.5.

Low intensity peaks at 2075 and $1980 \mathrm{~cm}^{-1}$ might suggest the presence of a minor proportion of $\mathrm{H}_{\text {trans }}$ in this sample. Furthermore, after the reactivation, the enzyme could be converted again completely into $\mathrm{H}_{\text {inact }}$ by air treatment (Fig. 3D and 4). Once more, the resulting sample could be converted into an active mixture of $\mathrm{H}_{\mathrm{ox}}$ and $\mathrm{H}_{\text {red }}$ (Fig. 3E and 4), with low intensity peaks at
2075 and $1987 \mathrm{~cm}^{-1}$ that might suggest the presence of a minor proportion of $\mathrm{H}_{\text {trans. }}$.

These results show that, in $\mathrm{CbA} 5 \mathrm{H}$, the transition $\mathrm{H}_{\text {ox }} / \mathrm{H}_{\text {inact }}$ is completely reversible in both directions and that several cycles can be repeated without damaging the structural and functional properties of the enzyme. Control experiments on the $\mathrm{O}_{2}$ sensitive CaHydA confirmed instead all the signatures ${ }^{15}$ of $\mathrm{O}_{2}$ damage (see Fig. S4).

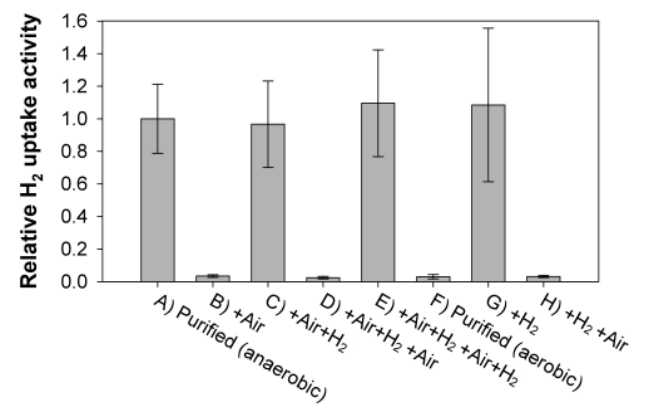

Figure 4. Enzyme activity of samples presented in figure 3.

Since $\mathrm{CbA5H}$ produced very intense and homogeneous $\mathrm{H}_{\text {inact }}$ spectra when exposed to air and the enzyme was stable, an aerobic purification was carried out. The enzyme was expressed under anaerobic conditions, but the purification was entirely carried out aerobically in the absence of dithionite.

The aerobically purified sample displayed a homogenous $\mathrm{H}_{\text {inact }}$ spectrum and it was catalytically inactive (Fig. 3F and 4). Also in this case, it was possible to reactivate completely the enzyme with a $\mathrm{H}_{2}$ treatment: this sample showed a mixture of $\mathrm{H}_{\mathrm{ox}}$ and $\mathrm{H}_{\mathrm{red}}$ signals and full $\mathrm{H}_{2}$ evolution activity (Fig. $3 \mathrm{G}$ and 4 ). Furthermore, this sample could be re-inactivated by air, displaying a homogeneous $\mathrm{H}_{\text {inact }}$ spectrum and strong activity loss (Fig. $3 \mathrm{H}$ and 4). The low intensity signal at $2014-2015 \mathrm{~cm}^{-1}$ present in most of the active $\mathrm{CbA} 5 \mathrm{H}$ samples might be an unassigned vibrational mode that was previously observed in reduced samples of $\mathrm{DdH} ;{ }^{21,22}$ alternatively, it might be due to a very low amount of $\mathrm{H}_{\mathrm{ox}}-\mathrm{CO}$, which is often found in $[\mathrm{FeFe}]$-hydrogenases preparations. The low intensity signals at 2098-2099 and $2003 \mathrm{~cm}^{-1}$ present in some of the inactive $\mathrm{CbA5H}$ samples could not be assigned to any previously described $\mathrm{H}$-cluster signal or redox state.

In conclusion, the data presented here show that in Clostridium beijerinckii $[\mathrm{FeFe}]$-hydrogenase $\mathrm{CbA} 5 \mathrm{H}$ the transition between the oxygen-sensitive catalytically active $\mathrm{H}_{\mathrm{ox}}$ state and the oxygen-stable inactive $\mathrm{H}_{\text {inact }}$ state is completely reversible. The transition can be driven by mild organic oxidants, such as thionine or DCIP, or simply by exposure to the oxygen present in air. Moreover, the transition $\mathrm{H}_{\mathrm{ox}} / \mathrm{H}_{\text {inact }}$ can be repeated several times (at least two), while in DdH after the first transition from $\mathrm{H}_{\text {inact }}$ to $\mathrm{H}_{\mathrm{ox}}$ the reverse reaction was impossible and oxygen damage was observed. 
These results give an original contribution to the discussion on oxygen sensitivity in $[\mathrm{FeFe}]$-hydrogenases, because they show that irreversible oxygen sensitivity is not an intrinsic property of the H-cluster, but it is very strongly influenced by the protein environment. It seems clear that, upon oxygen exposure, the protein environment of different enzymes can tune the fate of the $\mathrm{H}$ cluster towards an irreversible $\mathrm{O}_{2}$ damage or a completely reversible transition to the oxygen-stable $\mathrm{H}_{\text {inact }}$.

The exact mechanism in $\mathrm{CbA5H}$ is currently under investigation: more detailed experiments will be performed to assess if there are specific residues in the $\mathrm{H}$ domain that can influence the $\mathrm{H}_{\mathrm{ox}} / \mathrm{H}_{\text {inact }}$ transition or if this novel effect is more specifically due to the accessory domains present in this new enzyme (SLBB, 2[4Fe4S] ferredoxin-like).

Another important conclusion is that air does not cause any irreversible damage to the enzyme, since the transition $\mathrm{H}_{\mathrm{ox}} / \mathrm{H}_{\text {inact }}$ can be performed several times without any activity loss or spectral influence. The treatment did not result in significant appearance of $\mathrm{H}_{\mathrm{ox}}{ }^{-}$ $\mathrm{CO}$ state, typical signature of $\mathrm{H}$-cluster decomposition ${ }^{15}$.

Consequently, these data open completely new perspectives for the exploitation of [FeFe]-hydrogenases in real applications. The use of $\mathrm{CbA5H}$ (or engineered enzymes with similar properties) would make the enzyme preparation, manipulation and storage much simpler than with any other [FeFe]-hydrogenase and pave the way for applicative exploitation of these highly efficient biocatalysts in hydrogen producing devices.

\section{ASSOCIATED CONTENT}

\section{Supporting Information.}

The Supporting Information is available free of charge on the ACS Publications website (http://pubs.acs.org). Experimental details, Sequence alignment, FTIR spectra with all signals, control experiments on CaHydA (PDF).

\section{AUTHOR INFORMATION}

\section{Corresponding Authors}

*francesca.valetti@unito.it, *gianfranco.gilardi@unito.it

\section{Author Contributions}

$\$$ These authors contributed equally.

\section{Notes}

The authors declare no competing financial interests.

\section{List of abbreviations}

CbA5H: Clostridium beijerinckii [FeFe]-hydrogenase cluster A5. CaHydA: C. acetobutylicum [FeFe]-hydrogenase. DCIP: 2,6-dichlorophenolindophenol. DdH: Desulfovibrio desulfuricans [FeFe]-hydrogenase, $\mathrm{DvH}$ : D. vulgaris [FeFe]-hydrogenase. SLBB:soluble-ligand-binding $\beta$-grasp.

\section{Funding}

This work was supported by project HyStrEM (E.U. Structural Funds N.1083/2006 F.E.S.R. 2007-2013).

\section{REFERENCES}

(1) Vignais, P.M., and Billoud, B. (2007) Chem. Rev. 107, 42064272.

(2) Meyer, J. (2007) Cell. Mol. Life Sci. 64, 1063-1084.

(3) Winkler, M., Esselborn, J., and Happe, T. (2013) Biochim Biophys Acta 1827, 974-985.

(4) Lubitz, W., Ogata, H., Rüdiger, O., and Reijerse, E. (2014) Chem. Rev. 114, 4081-4148.

(5) Peters, J.W., Schut, G.J., Boyd, E., Mulder, D.W., Shepard, E.M., Broderick, J.B., King, P.W., and Adams, M.W.W. (2015) Biochim. Biophys. Acta 1853, 1350-1369.

(6) Morra, S., Arizzi, M., Allegra, P., La Licata, B., Sagnelli, F., Zitella, P., Gilardi, G., and Valetti, F. (2014) Int. J. Hydrogen Energy 39, 9018-9027.

(7) Morra, S., Valetti, F., Sarasso, V., Castrignanò, S., Sadeghi, S.J., and Gilardi, G. (2015) Bioelectrochemistry 106(Pt B), 258-262.

(8) Morra, S., Mongili, B., Maurelli, S., Gilardi, G., and Valetti, F. (2016) Biotechnol. Appl. Biochem. 63, 305-311.

(9) Vincent, K.A., Parkin, A., Lenz, O., Albracht, S.P.J., Fontecilla-Camps, J.C., Cammack, R., Friedrich, B., and Armstrong, F.A. (2005) J. Am. Chem. Soc. 127, 18179-18189.

(10) Stripp, S.T., Goldet, G., Brandmayr, C., Sanganas, O., Vincent, K.A., Haumann, M., Armstrong, F.A., and Happe, T. (2009) Proc. Natl. Acad. Sci. 106, 17331-17336.

(11) Lautier, T., Ezanno, P., Baffert, C., Fourmond, V., Cournac, L., Fontecilla-Camps, J.C., Soucaille, P., Bertrand, P., Meynial-Salles, I., and Léger, C. (2011) Faraday Discuss. 148, 385-407.

(12) Orain, C., Saujet, L., Gauquelin, C., Soucaille, P., MeynialSalles, I., Baffert, C., Fourmond, V., Bottin, H., and Léger, C. (2015) J. Am. Chem. Soc. 137, 12580-12587.

(13) Goldet, G., Brandmayr, C., Stripp, S.T., Happe, T., Cavazza, C., Fontecilla-Camps, J.C., and Armstrong, F.A. (2009) J. Am. Chem. Soc., 131, 14979-14989.

(14) Lambertz, C., Neidel, N., Havelius, K.G.V., Noth, J., Chernev, P., Winkler, M., Happe, T., and Haumann, M. (2011) J. Biol. Chem. 286, 40614-40623.

(15) Swanson, K.D., Ratzloff, M.W., Mulder, D.M., Artz, J.H., Ghose, S., Hoffman, A., White, S., Zadvornyy, O.A., Broderick, J.B., Bothner, B., King, P.W., and Peters, J.W. (2015) J. Am. Chem. Soc. 137, 1809-1816.

(16) Vincent, K.A., Parkin, A., and Armstrong, F.A. (2007) Chem. Rev. 107, 4366-4413.

(17) King, P.W. (2013) Biochim. Biophys. Acta 1827, 949-657.

(18) Adams, M.W.W. (1990) Biochim. Biophys. Acta 1020, 115145

(19) Fourmond, V., Greco, C., Sybirna, K., Baffert, C., Wang, P.H., Ezanno, P., Montefiori, M., Bruschi, M., Meynial-Salles, I., Soucaille, P., Blumberger, J., Bottin, H., De Gioia, L., Léger, C. (2014) Nature Chem. 6, 336-342.

(20) Bingham, A.S., Smith, P.R., Swartz, J.R. (2012) Int. J. Hydrogen Energy 37, 2965-2976.

(21) Roseboom, W., De Lacey, A.L., Fernandez, V.M., Hatchikian, E.C., and Albracht, S.P.J. (2006) J. Biol. Inorg. Chem. 11, 102-118.

(22) De Lacey, A.L., and Fernandez, V.M. (2007) Chem. Rev. 107, 4304-4330.

(23) van der Westen, H.M., Mayhew, S.G., and Veeger, C. (1978) FEBS Lett. 86, 122-126.

(24) Pierik, A.J., Hagen, W.R., Redeker, J.S., Wolbert, R.B., Boersma, M., Verhagen, M.F., Grande, H.J., Veeger, C., Mutsaers, P.H., Sands, R.H., and Dunham, W.R. (1992) Eur. J. Biochem. 209, 63-72.

(25) Pierik, A.J., Hulstein, M., Hagen, W.R., and Albracht, S.P.J. (1998) Eur. J. Biochem. 258, 572-578.

(26) Fernandez, V.M., Hatchikian, E.C., and Cammack, R. (1985) Biochim. Biophys. Acta 832, 69-79.

(27) Hatchikian, E.C., Forget, N., Fernandez, V.M., Williams, R., and Cammack, R. (1992) Eur. J. Biochem. 209, 357-365.

(28) van Dijk, C., van Berkel-Arts, A., and Veeger, C. (1983) FEBS Lett. 156, 340-344.

(29) Parkin, A., Cavazza, C., Fontecilla-Camps, J.C., and Armstrong, F.A. (2006) J. Am. Chem. Soc. 128, 16808-16815. 
(30) King, P.W., Posewitz, M.C., Ghirardi, M.L., and Seibert, M. (2006) J. Bacteriol. 188, 2163-2172.

(31) Morra, S.. Cordara, A.. Gilardi, G.. and Valetti, F. (2015) Protein Sci. 24, 2090-2094.

(32) Calusinska, M., Happe, T., Joris, B., and Wilmotte, A. (2010) Microbiology 156, 1575-1588.

(33) Burroughs, A.M., Balaji, S., Iyer, L.M., and Aravind, L. (2007) Biol. Direct. 2, 18-45.
(34) Silakov, A., Kamp, C., Reijerse, E., Happe, T., and Lubitz, W. (2009) Biochemistry 48, 7780-7786.

(35) Nicolet, Y., De Lacey, A.L., Vernède, X., Fernandez, V.M., Hatchikian, E.C., and Fontecilla-Camps, J.C. (2001) J. Am. Chem. Soc. $123,1596-1601$. 
Authors are required to submit a graphic entry for the Table of Contents (TOC) that, in conjunction with the manuscript title, should give the reader a representative idea of one of the following: A key structure, reaction, equation, concept, or theorem, etc., that is discussed in the manuscript. Consult the journal's Instructions for Authors for TOC graphic specifications.

Insert Table of Contents artwork here

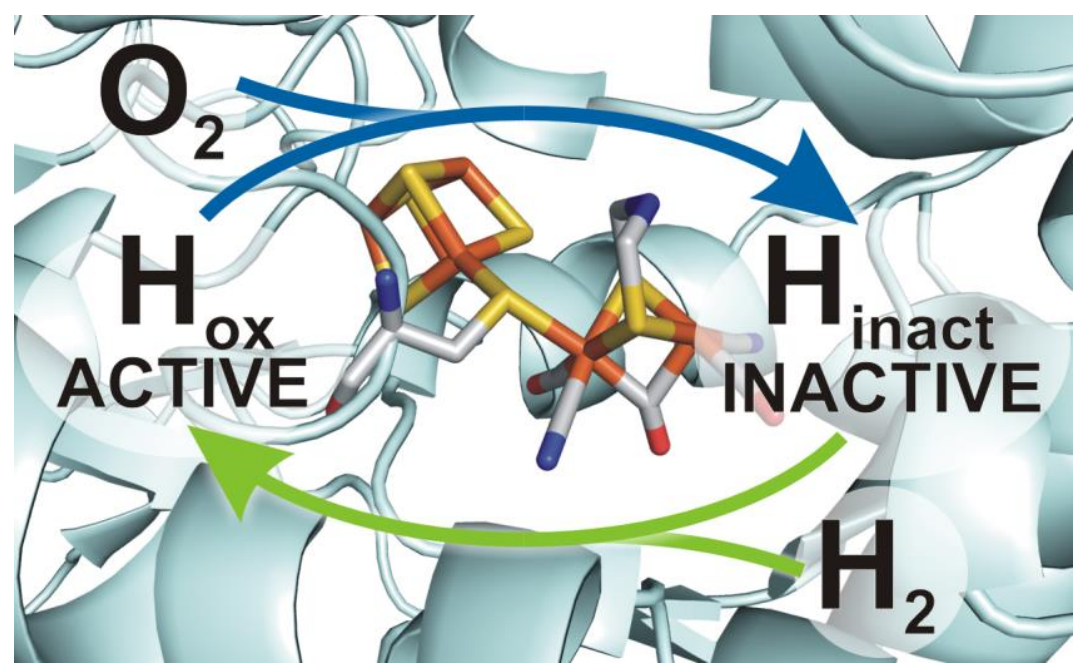

